\title{
THE POTENTIAL IMPACT OF IMPROVEMENTS IN CONTRACEPTION ON FERTILITY AND ABORTION IN WESTERN COUNTRIES *
}

\author{
Charles F. WESTOFF $* *$
}

Princeton University, USA

\section{Charles R. HAMMERSLOUGH}

University of Michigan, USA

\section{Lois PAUL}

Princeton University, USA

Received June 1987, final version received July 1987

Abstract. Survey information on fertility intentions, patterns of contraceptive use, contraceptive failures and abortions is used to develop estimates of unwanted births and of unplanned pregnancies for seven countries, by method of contraception. Potential improvements in contraception, leading to more use of highly efficient methods are considered, and several scenarios for improved contraceptive use are presented. The impact each would have on fertility levels and on abortion rates is estimated. Although improvements in contraception will have only a limited impact on fertility - which is already very low - their impact on abortion could be considerable.

Résumé. L'impact potentiel du progrès de la contraception sur la fécondité et l'avortement dans les pays occidentaux

Les auteurs utilisent des données d'enquêtes sur les intentions de procréation, le recours à la contraception, les échecs de la contraception et l'avortement pour évaluer les naissances non désirées et les grossesses non planifiées, selon la méthode de contraception utilisée, dans sept pays. Ils envisagent d'éventuels progrès de la contraception conduisant à un élargissement de l'emploi de méthodes très efficaces, et évaluent, dans différents scénarios de progrès du recours à la contraception, son impact sur les niveaux de la fécondité et de l'avortement. Si le progrès de la contraception n'aura qu'un effet limité sur la fécondité - déjà très basse - son impact sur les niveaux de l'avortement pourrait être considérable.

\footnotetext{
* Acknowledgements: This paper has benefitted from careful readings by Noreen Goldman, Norman Ryder, Gérman Rodríguez and Anne Pebley. We are also indebted to Elise F. Jones of the Alan Guttmacher Institute for some of the European data used here. A preliminary version of this paper was presented at the European Population Conference in Jyväskylä (Finland), 1987.

** Author's address: Office of Population Research, Princeton University, 21 Prospect Avenue, Princeton, NJ 08544, USA.
} 


\section{Introduction}

Fertility has declined to very low levels in the developed countries in general, including most of Europe. This decline is largely attributable to the widespread use of contraception. The methods used range considerably in efficacy from traditional to modern and surgical methods, though, and contraceptive failure remains a significant fact of life. High abortion rates bear ample testimony to contraceptive failures as well as to the non-use of contraception, especially among the young. Low fertility can be regarded as a joint consequence of births averted by contraception and abortion, and abortion can be thought of as a consequence of unintended pregnancy occurring either through contraceptive failure or through failure to use contraception.

This paper addresses the question of the potential demographic impact on fertility and on abortion of various possible improvements in contraceptive practice. Improvements in contraceptive practice can assume different forms, including the emergence of new technology or an increase in the proportion of couples who use more effective methods. Use of more effective methods, in its turn, could result from their greater acceptability because of technical improvements.

European fertility is the primary focus here, and our data are derived from six European fertility surveys selected primarily because of the inclusion of some of the kinds of data needed, such as fertility intentions and contraceptive-exposure status, and the availability of abortion data from other sources. Several other countries could have been included, but the ones selected provide considerable variety in contraceptive practice. The United States is also included, not just for comparative purposes, but to provide some of the needed information not available from the European surveys.

In the first part of the paper we assess the potential impact on fertility of contraceptive improvements that would reduce the number of unwanted births, defined as births occurring after the last wanted birth. In the second part we address unplanned births, defined to include mistimed as well as unwanted births, in order to assess the potential impact of contraceptive improvements on induced abortion rates. 


\section{Potential for further fertility reductions resulting from improved contraception}

In the low-fertility populations of interest, the births that are important to consider here are the unwanted births, defined as births occurring after the last wanted birth. Although period fertility rates can be influenced by shifts in the timing of births - the well-known experience of many western countries that have seen postponements of marriage and delays of childbearing - the intrinsic rate of growth in a population where fertility is around replacement will be largely unaffected by the length of time it takes to have the two births. Thus, our concern is with the rate of unwanted fertility, that is, the excess fertility that theoretically would not occur if all women exposed to the risk of unwanted conception were to use perfect contraception. We ask how much additional reduction in the fertility rates of countries already experiencing very low fertility would result from varying approximations to perfect fertility control. The probability of aborting an unwanted pregnancy also enters this equation, but our initial focus is on the effects of contraceptive improvement on the unwanted-pregnancy rates. We limit our attention here to contraception among that segment of the population that intends to have no more births, i.e., the proportion that is exposed to the risk of an unwanted birth. When we turn in the next section to estimating the potential impact of contraceptive improvements on the abortion rate, we shall look at contraception in the entire population of women of childbearing age: this is because the abortion rate reflects the incidence of mistimed pregnancies among women who have not yet reached the end of their desired childbearing as well as some unwanted pregnancies among those who have already reached it.

In this initial section dealing with unwanted births, we shall first present estimates of the proportions of women in each country who are exposed to the risk of an unwanted birth. We shall then examine country-specific data on patterns of contraceptive use, and combine these with the more limited data available on unwanted pregnancies specific by type of contraceptive use, in order to estimate the numbers of unwanted pregnancies by country and contraceptive method. Adjustment for spontaneous and induced abortion then yields estimates of the numbers of unwanted births. Finally, we examine the impact that improved contraception might have on these numbers and hence on overall fertility levels. 


\subsection{The proportion of women at risk of unwanted fertility}

The estimates in the first column of table 1 show the percentage of married women who want to have no more births, derived from surveys conducted between 1977 and 1983. The assumption of comparability of these estimates is only the first of many heroic assumptions contained in this analysis. In some countries (e.g., Sweden, the U.S.), the estimate is derived from direct questions about intentions, in others (e.g., France, Norway) by comparing women's stated desired or expected family size with their actual current family size. The surveys also vary in the age range sampled, including definitions of ages 15-44, 18-44, 20-44 and 18-37. The figures presented in table 1 have been adjusted where necessary to provide estimates for a population of married women $15-44$ years of age. Roughly 50 to nearly 70 per cent of married

Table 1

Estimation of the percentage of women aged $15-44$ who want no more births: selected countries, circa 1981.

\begin{tabular}{|c|c|c|c|}
\hline & $\begin{array}{l}\text { Percentage of married } \\
\text { women aged } 15-44 \text { who } \\
\text { want no more births }\end{array}$ & $\begin{array}{l}\text { Percentage of all } \\
\text { women aged 15-44 who } \\
\text { are in union }\end{array}$ & $\begin{array}{l}\text { Percentage of all } \\
\text { women aged } 15-44 \text { who } \\
\text { want no more births } a, b,\end{array}$ \\
\hline Finland & 49 & 64 & 40 \\
\hline France & 63 & 67 & 46 \\
\hline Netherlands & 50 & 66 & 37 \\
\hline Norway & 68 & 64 & 48 \\
\hline Sweden & 60 & 69 & 47 \\
\hline U.K. & 54 & 69 & 41 \\
\hline U.S.A. & 63 & 65 & 45 \\
\hline
\end{tabular}

a 'Want no more' is measured in different ways in the different surveys (see text). The estimates here are for married women aged 15-44 from survey data based on different age ranges such as 18-44. The national surveys concerned were conducted between 1977 and 1983 (see table 2 for the exact dates).

${ }^{b}$ Estimated as the sum of the percentage of women married and the percentage who are cohabiting informally, derived from a variety of special studies, circa 1981.

c Product of the figures in the first two columns, itself expressed as a percentage, plus the percentage of all women who are not in union and aged 35-44.

Sources: General: United Nations, Demographic Yearbook 1982 and Höpflinger (1985); Finland: Aromaa et al. (1983); the Netherlands: Koesoebjono (1986, p. 377); Norway: Noack and Østby (1981, p. 203); Sweden: Arvidsson et al. (1984, pp. 8-9). 
women of reproductive age in these countries intend to have no more births and are therefore exposed to the risk of an unwanted pregnancy.

Since we want to evaluate the impact of contraception on fertility, we are interested in the population of all women, not just married women. The second column of table 1 shows our estimates of the proportions of women in union (circa 1981), including informally cohabiting women as well as the legally married. The marriage data originate in the countries' official statistical records, and the estimates of informal cohabitation are drawn from various special studies. There is obviously some guesswork here. The resulting range of estimates of the proportions of women in union varies little among the seven countries: on average about two-thirds of women aged 15-44 are in a union.

The third column of table 1 estimates the percentage of all women, regardless of marital status, who want no more births. The survey data on fertility intentions available to us refer to married women only for several of the countries; we have little information about the intentions of unmarried (single, divorced or widowed) women. We have incorporated into our estimates the assumption that all unmarried women 35-44 intend to have no more births and that unmarried women 15--34 intend to have (more) children. Clearly this assumption leads to an overestimation of the proportion of older women at risk of an unwanted birth, but the error is probably more than offset by the large number of younger, unmarried women who actually intend no future childbearing. Thus the overall bias probably has the conservative effect of underestimating the proportion of all women who want no more births, which in turn would slightly underestimate the fertility-reducing effect of improved contraception. We see in table 1 that an estimated $37-48$ per cent of all women of reproductive age want no more births and thus are exposed to the risk of an unwanted pregnancy.

\subsection{Contraceptive methods used}

The distribution of types of contraceptive exposure for married women who want no more births is shown in table 2, based on the most recent survey data for the seven countries. Although currently pregnant women are not at risk of having an unwanted pregnancy, they or their exposure should be included in the total denominator. For reasons of 
Table 2

Estimated percentage of (non-pregnant) married women aged 15-44 who want no more births, by type of exposure to the risk of pregnancy: selected countries, circa 1983.

\begin{tabular}{lccccrrr}
\hline Exposure & $\begin{array}{l}\text { Finland } \\
1977\end{array}$ & $\begin{array}{l}\text { France } \\
1978\end{array}$ & $\begin{array}{l}\text { Netherlands } \\
1982\end{array}$ & $\begin{array}{l}\text { Norway } \\
1977\end{array}$ & $\begin{array}{l}\text { Sweden }^{*} \\
1981\end{array}$ & $\begin{array}{l}\text { U.K. } \\
1983\end{array}$ & $\begin{array}{l}\text { U.S.A. } \\
\text { (whites) } \\
1982\end{array}$ \\
\hline Pill & 10 & 26 & 26 & 13 & 18 & 17 & 7 \\
Sterilization & 8 & 5 & 40 & 10 & 5 & 37 & 50 \\
IUD & 28 & 10 & 11 & 31 & 25 & 8 & 5 \\
Condom & 26 & 7 & 7 & 17 & 20 & 13 & 8 \\
Other methods & 5 & 34 & 2 & 12 & 5 & 8 & 9 \\
Sterile & 11 & 10 & 10 & 9 & 10 & 9 & 14 \\
Not using method & 12 & 8 & 4 & 8 & 9 & 8 & 6 \\
Total & 100 & 100 & 100 & 100 & 100 & 100 & 100 \\
\hline
\end{tabular}

${ }^{a}$ Women who reported they had not sexual relations in the preceding four weeks have been redistributed proportionately.

data availability, however, they have been excluded. ${ }^{1}$ One could argue that sterile women are also not at risk, but since this category contains a wide variety of types of sterility (including women who have been exposed for a long time and those who believe they are infecund) ${ }^{2}$ it is reasonable to assume some very low risk.

The seven countries can be divided roughly into three groups with regard to their contraceptive practices: those with a high prevalence of contraceptive sterilization (the Netherlands, U.K., U.S.); the Scandinavian countries, with a more diversified picture concentrating on the IUD and the condom; and France, which shows a heavy reliance on the pill and on 'other' methods, a residual category that includes withdrawal, diaphragm, rhythm, douches and spermicidal creams. In France, withdrawal is the dominant method in this category. From the distributions, one would infer that the Netherlands, with

1 The difficulty is that we cannot determine from the European surveys what fraction of the women who report that they are pregnant and that they intend no more births, regard the current pregnancy as unwanted or as the last wanted pregnancy. In the U.S. data, the actual proportion of gestation time for unwanted pregnancies tabulated in the 12-month period amounted to only one per cent, so its inclusion would not appreciably affect the distributions of other types of exposure. ${ }^{2}$ The classification of the non-contraceptively sterile is especially problematic for these intercountry comparisons because of differences in definitions and in whether reportedly sterile women were asked questions about fertility intentions. It is likely that the apparent higher incidence of sterility in the U.S. estimated for women who intend no more births is more a result of methodological than of real differences. 
two-thirds of the women at risk using either the pill or sterilization, would have the lowest unwanted pregnancy rates: this expectation is supported in the subsequent analysis.

A small but important fraction of women report not using any method despite their intention to avoid further childbearing. This is undoubtedly a heterogeneous group of women, some of whom may be separated from their husbands temporarily, some who may have low coital frequency, other couples who may be subfecund, and still others who may not use contraception for aesthetic or moral reasons or because of inconvenience. One would normally expect this group as a whole to have higher pregnancy rates than women using contraception.

\subsection{Estimating pregnancy rates for each type of contraceptive method}

\subsubsection{Available data}

The major data deficiency for the six European countries in this analysis is the lack of reliable information on observed failure rates for different contraceptive methods. Special efforts to collect such data using a retrospective monthly calendar approach have been undertaken in three U.S. surveys, and we shall apply failure rates calculated for white women from the most recent U.S. survey to the European distributions of methods. At first glance, this seems like an unwarranted assumption. How can we assume that Americans (even confining the experience to white Americans) and the Finns or the French or the British use particular methods with the same effectiveness? There are two supporting arguments.

The first is the simple proposition that the failure rates for certain methods, such as surgical sterilization and the IUD, are largely independent of behavioural variability. Although one might argue that medical practices and technology can vary across countries, the overwhelming presumption is that these two methods are essentially "culture free'. The pill is more sensitive to variations in practice than the former two methods, and the compounds most used may differ, but there is little basis for any clear theory about national differences. It seems reasonable to assume that the pill is used with similar degrees of effectiveness in all these countries.

The argument that failure rates in the U.S. can be assumed to operate in Europe becomes less tenable when it is applied to the condom or other methods, such as withdrawal or periodic abstinence, 
because their use is more subject to human error, and this might vary among users of different nationalities. One must also keep in mind here the fact that people are not randomly distributed among methods; there is no doubt a considerable amount of selectivity in the use of different methods, a selectivity that is probably connected with the proportion of couples using the method. This issue further complicates the whole picture.

Nonetheless, contraceptive sterilization, the pill, and the IUD are probably used now by the majority of married couples who want no more children. And it is important to remember that some of these surveys were conducted a decade ago and that the use of these modern methods has no doubt increased since then. We still know little about the selectivity of women who are not using any method at all or who are classified as sterile and how this varies among countries; this subject could be analyzed profitably in a cross-country context.

The second supporting argument is based on indirect empirical evidence. In table 3, we have assembled age-specific pregnancy rates estimated for each of the seven countries, based on registered births and abortions in 1983. Women who want no more births are concentrated in the older age groups (over 30 or over 35 ), but there appears to be little variation in pregnancy rates across these countries at these ages. The Netherlands is an exception to this generalization, with lower pregnancy rates than the other countries, consistent with our earlier observation of greater use of more effective methods. It is closely paralleled by the U.S. which has the highest prevalence of

Table 3

Pregnancy rates a per 1000 women aged 15-44, by age of women: selected countries, 1983.

\begin{tabular}{lccccccc}
\hline Age & Finland & France & Netherlands & Norway & Sweden & U.K. & U.S.A. (whites) \\
\hline $15-19$ & 34 & 24 & $\mathbf{1 4}$ & 41 & 32 & 44 & 81 \\
$20-24$ & 106 & 126 & 75 & 119 & 111 & 116 & 144 \\
$25-29$ & 138 & 156 & 137 & 136 & 143 & 139 & 131 \\
$30-34$ & 87 & 89 & 76 & 82 & 93 & 82 & 77 \\
$35-39$ & 42 & 40 & 22 & 33 & 41 & 30 & 28 \\
$40-44$ & 14 & 11 & 5 & 10 & 14 & 8 & 6 \\
\hline
\end{tabular}

${ }^{2}$ Calculated by summing the age-specific birth rates and abortion rates.

Sources: Abortion rates: Tietze and Henshaw (1986, table 5) and DNSEE (1984, p. 109); birth rates: United Nations Demographic Yearbook. 
contraceptive sterilization. We should note though that the similarity of the aggregate pregnancy rates for older women is of course not conclusive evidence that different methods are used with similar efficacy; moreover, countries may also vary in the postponement of wanted births to older ages.

The combined weight of these arguments suggests that the methodspecific failure rates observed in the U.S. may reasonably be assumed to approximate the experience of older married European women.

\subsubsection{Measurement of contraceptive failure}

A considerable literature on the measurement of the use-effectiveness of contraception has now accumulated [Trussell and Kost (1987)]. Early studies relied on the Pearl rate, which simply divided unintended pregnancies by the number of women-months of exposure to risk with particular methods and expressed this as an annual rate. After some 30 years of use, this technique was replaced by the life-table method, which corrected an important deficiency of the Pearl rate. Because of the heterogeneity introduced by the less successful users who become pregnant in the early months of use, the Pearl rate declines with the length of the observation period. The life-table method corrects this deficiency by taking duration of use into account. Typically, failure is measured as the proportion of women using a method who become pregnant in the first year of use. ${ }^{3}$ This procedure represents a distinct methodological improvement over the Pearl rate in that it provides a uniform duration of use within which to compare the effectiveness of different methods. Although such rates, based on the U.S. National Survey of Family Growth, have been calculated and are available, we have chosen not to use them here and to rely instead on simple cross-sectional one-year ratios of conceptions to exposure. There are several reasons for this choice.

The objectives of this paper are demographic: to evaluate the potential long-run impact on fertility and abortion rates of an improvement in the effectiveness of contraception. The results are not intended as a tool for counselling women about the comparative risks and benefits of particular methods. The study therefore focusses on a cross-section of

3 'First year of use' is itself something of a misnomer, since the estimate refers to experience during the first year of use following a pregnancy, which may be the $n$th time the woman has ever used the method. 
contraceptive experience at a point in time that reflects exposure at varying durations of use. We are not interested in the experience of women during their first year of use of a method, but rather in the average one-year experience of a population made up of women at varying durations of use. Our procedure is the appropriate one for estimating the actual fertility impact of contraception, but it is not a reliable guide for comparing the effectiveness of methods because it may be capturing experience at different durations of use.

\subsubsection{Imputation of exposure to the risk of unwanted pregnancy}

Our focus is on women who want no more births and who are, therefore, exposed to the risk of unwanted pregnancy, because it is the births to this group that will make a difference in low fertility populations. This sub-set of women typically uses contraception more effectively than the group of women who want more children. Aside from the obvious differences involved in the choice of sterilization among women who want no more births, the evidence is clear that such women use all methods more effectively [see, for example, Sagi et al. (1962) and Ryder (1973)]. Whether this is because of higher motivation, reduced coital frequency, or additional experience is unclear, but the failure rates are consistently lower for this group. It has now become common practice to divide women into those who currently want more and those who want no more births and to calculate rates for each group separately. In this exercise we follow a similar procedure, but attempt one theoretical improvement in the measure. Instead of using the woman's current intention (the intention reported at the interview), we attempt to impute her intention at the beginning of the observation period. With only the current intention, one can determine whether the pregnancy was unwanted for couples who had a pregnancy, but we do not have a firm grasp on the length of exposure to risk of an unwanted birth for these women or for the women who do not become pregnant. In short, from the current preference alone, we cannot assess the true preference at the beginning of the observation period. ${ }^{4}$ The practical effect of imputing preferences when calculations are confined to the 12 to 24 months immediately preceding the survey is probably not great, but the logic is tidier. We imputed the intention at a point 15 months prior to the interview (see the appendix for details) and then calculated

\footnotetext{
4 This point was made some years ago by Norman Ryder and more recently by Noreen Goldman.
} 
conception rates for the following 12-month period. The three months immediately prior to the interview were excluded in order to ensure enough time for currently pregnant women to be able to recognize that they were pregnant. Note that it is conceptions in the 12 months that are counted, not pregnancy outcomes. Thus all pregnancies are included regardless of whether they terminated in live births, stillbirths, abortions or miscarriages. Pregnancies still in progress at the end of the 12 months are also counted. For all women, each of the 12 months was classified by type of exposure, and each conception reported (all of which were unwanted by our definition) was assigned to a particular method on the basis of the woman's report of the method she was using when she became pregnant and by examination of the 12-month calendar.

\subsection{Estimated levels of unwanted fertility}

We are now in a position to combine the estimates of method-specific failure rates with the patterns of contraceptive use, in order to estimate the number of unwanted pregnancies per 1000 women at risk per year, broken down by contraceptive method. The results of this procedure are presented in table 4 for the 1982 U.S. data. A few comments are required. The failure rate for contraceptive sterilization was empirically calculated from these data at 0.0014 per woman per year. Research evidence on this subject in general is inadequate: we can note that

Table 4

Pregnancy rates and exposure to the risk of pregnancy for recent 12 month period, for married women who want no more births, by type of exposure: U.S.A. (whites), 1982.

\begin{tabular}{llll}
\hline Type of exposure & $\begin{array}{l}\text { Pregnancy rate per } \\
12 \text { months of exposure } \\
(p)\end{array}$ & $\begin{array}{l}\text { Proportion of } \\
\text { exposure } \\
(w)\end{array}$ & $\begin{array}{l}\text { Pregnancies } \\
\text { per year }(1000) \\
(p) *(w)\end{array}$ \\
\hline Pill & 0.014 & 0.08 & 1.1 \\
Sterilization & 0.0014 & 0.51 & 0.7 \\
IUD & 0.066 & 0.05 & 3.3 \\
Condom & 0.021 & 0.08 & 1.7 \\
Other methods & 0.084 & 0.09 & 7.6 \\
Sterile & 0.003 & 0.14 & 0.4 \\
Not using method & 0.217 & 0.05 & 11.5 \\
Total & 0.026 & 1.00 & 26.3 \\
\hline
\end{tabular}


Trussell and Kost (1987) offer a best estimate of 0.004 based on various bits of evidence.

The pregnancy rate for women reporting themselves as sterile is a sheer guess and is set at 0.003 , twice the observed failure rate of the contraceptively sterilized. There must be some pregnancies among women who report themselves as unable to conceive. The difficulty is that we cannot satisfactorily impute the date of the onset of sterility (except for surgical procedures), so we rely here on a current status measure.

The pregnancy rate for periods of non-use (0.22) seems low, but one must remember that the five per cent of women who are not using any contraceptive method among women who want no more children are no doubt a highly select group.

In general, the failure rates are ranked in the expected order ${ }^{5}$, except perhaps for the condom, which here shows a lower rate than the IUD. As noted above, however, these measures are designed to estimate the actual number of unwanted pregnancies by contraceptive method, not to compare the effectiveness of different methods: the former requires that differences in duration of use be embodied in the estimates whereas the latter would require control for any such differences. Moreover, a 12-month observation period is short for a sample of this size (1,566 women are represented in the 'want no more' category). To check the stability of these estimates, we repeated all calculations for a 24-month period, but both the method pattern and the total unwanted-pregnancy rate remained unchanged.

The remaining columns of table 4 calculate the average of the various method-specific failure rates, each weighted by the proportion of the total exposure contributed by the method concerned. The overall result is that over the 12-month period during 1981-1982 in the United States, married women who intended to have no more births were practising contraception at a level that would lead to an annual rate of 26 unwanted pregnancies per 1000 women. What can we say about the reasonableness of this estimate?

An annual unwanted pregnancy rate of 0.026 per woman would yield a cumulative synthetic proportion having an unwanted pregnancy over a 10 -year period of 23 per cent $\left[1-(1-p)^{10}\right]$. A period of ten

\footnotetext{
5 The failure rates for the main methods combined in the 'other methods' category are 0.04 for the diaphragm, 0.18 for withdrawal and 0.16 for periodic abstinence.
} 
years is used here simply as an illustration of a likely average number of years of the reproductive span remaining after the last wanted birth. Is this a 'reasonable' estimate? Another way to approach the question is to compare the 0.026 rate with the proportion of births reported as 'unwanted' in the survey. The following describes the steps in the calculation:

- Expected unwanted pregnancies per 1000 married women who want no more births

- The proportion of married women who want no more births

- Expected unwanted pregnancies per 1000 married women $\equiv 16.6$

- Proportion of unwanted pregnancies that result in live births

- Expected unwanted births per 1000 married women

- Annual births per 1000 married women 15-44, 1978-82

- Percentage of births to married women in the five years preceding the survey that were unwanted

This result compares favourably with the reported 6.1 per cent of births to married white women that were unwanted in the five years prior to the U.S. 1982 survey [Pratt et al. (1984)].

In one sense this is only a test of internal consistency in that it recaptures unwanted births that are in the numerator of the pregnancy rates. But it is also more than that in the sense that it indicates that the unwanted pregnancy rates attributed to the various methods yield a reasonable aggregate estimate of unwanted births.

In order to translate the number of unwanted pregnancies to the number of unwanted births, we need an estimate of the foetal-death rate for these pregnancies. The estimate used in our calculation is taken directly from the survey data for the 12 -month period ending nine months before the interview (to permit time for all pregnancy outcomes to be observed). It indicates that 56 per cent of these unwanted pregnancies either miscarried (17 per cent) or were aborted (39 per cent). Since these estimates are subject to considerable sampling error, the 18-month record was also examined: it shows 53 per cent terminated ( 22 per cent by miscarriages, 31 per cent by abortions). With an estimated 44 per cent of unwanted pregnancies leading to a live birth (based on the 12-month record) we obtain an estimate of 7.3 unwanted 
births per year per 1000 married women aged $15-44$, or 7.7 per cent of all births. If the 47 per cent survival rate (based on the 18-month record) is used instead, the net result is an estimated 8.2 per cent of births unwanted. Nonetheless, both estimates -7.7 and 8.2 per cent are close enough to 6.1 per cent to provide some assurance that the procedure is reasonably robust.

The estimate of roughly 50 per cent for the proportion of unwanted pregnancies ending in foetal mortality seems high. This is particularly so when we remember that induced abortion rates are typically seriously under-reported in fertility surveys. The abortion estimates from the 1982 National Survey of Family Growth have been compared with the national reporting system of the Centers for Disease Control and with the Alan Guttmacher Institute's periodic surveys of abortion providers, and the comparison shows an overall under-reporting of about 50 per cent. However, the reporting was particularly poor among the young, the unmarried and the black population, but there seemed to be little under-reporting among the older, married white women, which is the group studied here. We should also bear in mind that these data refer to older women who want no more births at all.

We have no reliable information on abortions from the European surveys, although official abortion statistics are available for all the countries included. One rough way to gauge the level of the abortion rate among women who want no more births is to compare the official European ratios of abortions to pregnancies for women 40 years of age and older (for whom it is reasonable to assume that most pregnancies are unwanted) with those of the United States. Over the three years prior to the surveys, the proportion of pregnancies aborted for women 40 and over was about 50 per cent higher in the Scandinavian countries and 40 per cent higher in France ${ }^{6}$ than in the U.S., about the same in the U.K. and about 10 per cent lower in the Netherlands. Applying these adjustment factors to the proportion of reported unwanted pregnancies aborted in the U.S. (but assuming the same miscarriage proportions), permits a crude measure that can be utilized in the estimate of unwanted births in these countries. These calculations are summarized

${ }^{6}$ The reported abortion rates for France have been doubled because of estimates of a 50 per cent under-reporting of abortion in the 1976 period [Tietze and Henshaw (1986)]. This may be too large an adjustment for the experience of older married women who, as in the U.S., may report abortions more reliably than younger women. 
Table 5

Estimated annual pregnancies per year per 1000 married women aged 15-44 who want no more births, by type of exposure, and estimated unwanted births: selected countries, circa 1981.

\begin{tabular}{|c|c|c|c|c|c|c|c|}
\hline Type of exposure & Finland & France & Netherlands & Norway & Sweden & U.K. & U.S.A. (whites) \\
\hline & \multicolumn{7}{|c|}{ Pregnancies per 1000 married women who want no more births } \\
\hline Pill & 1.4 & 3.6 & 3.6 & 1.8 & 2.5 & 2.4 & 1.1 \\
\hline Sterilization & 0.1 & 0.1 & 0.6 & 0.1 & 0.1 & 0.5 & 0.7 \\
\hline IUD & 18.5 & 6.6 & 7.3 & 20.5 & 16.5 & 5.3 & 3.3 \\
\hline Condom & 5.5 & 1.5 & 1.5 & 3.6 & 5.9 & 2.7 & 1.7 \\
\hline Other methods & 4.2 & 28.6 & 1.7 & 10.1 & 4.2 & 6.7 & 7.6 \\
\hline Sterile & 0.3 & 0.3 & 0.3 & 0.3 & 0.3 & 0.3 & 0.4 \\
\hline \multirow[t]{2}{*}{ Not using method } & 26.0 & 17.4 & 8.7 & 17.4 & 19.5 & 17.4 & 11.5 \\
\hline & \multicolumn{7}{|c|}{ Total unwanted pregnancies per 1000 married women who want no more births } \\
\hline \multirow[t]{13}{*}{ Total } & 56.0 & 58.1 & 23.7 & 53.5 & 49.0 & 35.3 & 26.3 \\
\hline & \multicolumn{7}{|c|}{ Estimated proportion of unwanted pregnancies resulting in live births } \\
\hline & 0.24 & 0.29 & 0.49 & 0.26 & 0.23 & 0.42 & 0.44 \\
\hline & \multicolumn{7}{|c|}{ Derived unwanted births per 1000 married women who want no more births } \\
\hline & 13.4 & 16.8 & $11.6^{2}$ & 13.9 & 11.3 & 14.8 & 11.6 \\
\hline & \multicolumn{7}{|c|}{ Proportion of all women who want no more births (from table 1 , column 3) } \\
\hline & 0.40 & 0.46 & 0.37 & 0.48 & 0.47 & 0.41 & 0.45 \\
\hline & \multicolumn{7}{|c|}{ Expected unwanted births per 1000 women } \\
\hline & 5.4 & 7.7 & 4.3 & 6.7 & 5.3 & 6.1 & 5.2 \\
\hline & \multicolumn{7}{|c|}{ General Fertility Rate (GFR) in five years preceding the survey (per 1000) } \\
\hline & 61 & 69 & 57 & 64 & 59 & 64 & 63 \\
\hline & \multicolumn{7}{|c|}{ Percentage of GFR unwanted } \\
\hline & 8.8 & 11.2 & 7.5 & 10.4 & 9.0 & 9.5 & 8.2 \\
\hline
\end{tabular}

in table 5, which first estimates the number of expected unwanted pregnancies per year by method for each of the countries (the product of European exposure distributions and U.S. method-specific failure rates). The summary statistic over all methods shows the total unwanted-pregnancy rate per 1000 married women who intend to have no more births. With the exception of the Netherlands, these estimates are higher than in the U.S., in some countries more than twice as high. This is simply because contraceptive sterilization dominates the picture in the United States while methods with higher failure rates are more commonly used in most of the other countries.

The estimated total unwanted-pregnancy rate for married women who intend no more births is then reduced by multiplying both by the 
proportion of such pregnancies estimated to end in live births and by the proportion of all women who want no more births. This leads to an estimate of the expected number of unwanted births per year per 1000 women (all women aged 15-44, regardless of marital status and fertility intentions) which when divided by the General Ferility Rate for the period yields an estimate of the proportion of all births that were unwanted.

Only in three of the countries besides the U.S. do the surveys include any information permitting other estimates of the proportion of unwanted births. In Finland and France, these estimates are in the vicinity of 8-9 per cent for the five years preceding the survey ${ }^{7}$ and in Sweden 3 per cent. It can be seen that our estimates for Finland and France correspond quite well with these, but that our estimate for Sweden is too high. The estimates of the abortion rate may be too low or the assumed failure rates may be too high for Sweden; alternatively, the unwanted births may be under-reported. There are obviously several points in our estimating procedure that are vulnerable to inadequate data, not the least of which are the original survey measures of unwanted births.

At any rate, the estimates are close enough to lend some confidence to the procedure and to its assumptions. The next and final step is to generalize the procedure to estimate the potential impact of contraceptive improvements on fertility.

\subsection{The impact of potential improvements in contraceptive technology and use}

On the basis of the estimated contributions to unwanted pregnancies in table 5 , one can state immediately that the most effective route to reducing unwanted pregnancy would be to reduce the proportion of women not using any method. The percentages not using contraception may not seem very high - ranging between 4 and 12 per cent across the seven countries (table 2) - but they have a major impact on the unwanted-pregnancy rate, contributing from a third to a half of all unwanted pregnancies. The women in this category are probably selected for low fecundity, low coital frequency and for other characteristics that might facilitate not having any additional births, but they

\footnotetext{
${ }^{7}$ Estimated from life-time proportions of 10 and 11 per cent.
} 
nevertheless make substantial contributions to the total number of unwanted pregnancies.

There are essentially three types of experience reflected in table 5: the French, with the highest rate of unwanted pregnancy, reflecting reliance on 'other methods' (mainly withdrawal and rhythm) ${ }^{8}$ and non-use; the Scandinavian countries, also with high rates, with the major components being the IUD and non-use; and the Netherlands, the U.K. and the U.S., with low rates, where non-use and 'other methods' in the latter two countries are the major source of unwanted pregnancy. The last three countries, of course, achieve their overall low rate by heavy reliance on contraceptive sterilization (see table 2).

What is the future of unwanted fertility in western countries? At present, the impact on general fertility is low - certainly under 10 per cent, perhaps closer to 5 per cent. But that is significantly affected by the high induced and spontaneous abortion rates. Without the high induced abortion rates, the unwanted birth rates would be at least twice as high, probably even higher than that. The proportion of the general fertility rate composed of unwanted births depends also on the number of children desired, which we have defined here on the basis of the proportion of women who want no more births. The desired number could, of course, increase in the future, but history shows little evidence for this other than, possibly, the temporary post-war baby boom in several countries which cannot be regarded as a major shift in fertility norms. The trend of contraceptive technology is also in the direction that promises reduced failure rates, and abortion has become more widely available. Again there could be changes in these trends: in the U.S., for example, the IUD is now largely unavailable because of the high costs of litigation arising out of court cases, and there possibly could be new restrictions on abortion. But the general trend seems clear enough. New methods do not exactly abound yet, although the new French abortion pill known as RU-486 promises to reduce unwanted fertility [Brody (1986)] and other developments, particularly in hormonal contraception, will undoubtedly emerge. In the meantime,

\footnotetext{
${ }^{8}$ Probably three-quarters of the use of 'other methods' by older couples in France is use of withdrawal, with rhythm contributing about ten per cent of that category [see World Fertility Survey $(1981$, p. 11)]. If these components were assigned method-specific failure rates in these proportions, the overall failure rate for the 'other methods' category would be nearly twice as high as the rate utilized in these calculations. The implication of the lower rate is that the French are using withdrawal with greater efficacy than the Americans.
} 
Table 6

Models of improved contraceptive practice for married women aged 15-44 who want no more births.

\begin{tabular}{|c|c|c|c|c|}
\hline \multirow[t]{2}{*}{ Type of exposure } & \multicolumn{4}{|c|}{ Model } \\
\hline & A & B & $\mathrm{C}$ & $\mathrm{D}$ \\
\hline & \multicolumn{4}{|c|}{ Percentage using method } \\
\hline Pill & 25 & 25 & 30 & 20 \\
\hline Sterilization & 50 & 25 & 20 & 35 \\
\hline IUD & 5 & 15 & 13 & 11 \\
\hline Condom & 5 & 15 & 20 & 17 \\
\hline Other methods & 1 & 6 & 3 & 3 \\
\hline Sterile & 12 & 12 & 12 & 12 \\
\hline Not using method & 2 & 2 & 2 & 2 \\
\hline \multirow[t]{3}{*}{ Total } & 100 & 100 & 100 & 100 \\
\hline & \multicolumn{4}{|c|}{$\begin{array}{l}\text { Total unwanted pregnancies per } 1000 \text { married women } \\
\text { who want no more births a }\end{array}$} \\
\hline & 15.5 & 21.8 & 27.3 & 23.5 \\
\hline
\end{tabular}

${ }^{a}$ Product of method-specific unwanted-pregnancy rate for U.S. married, white women aged 15-44 who want no more births and the model distributions for percentages using the method.

there will probably be increased shifts to contraceptive sterilization, as has happened in several countries over short periods of time. This trend would be accelerated if more progress were to be made on developing techniques to reverse these procedures.

We can speculate about the impact of various plausible shifts toward the use of the more effective existing methods without imagining methods of the future. The distribution of methods used in the Netherlands is one that is highly effective, although the Dutch population, like the population of the U.K. and the U.S., may be too reliant on surgical sterilization to serve as a model for other countries. Table 6 presents a variety of models, all with lower total unwanted pregnancy rates (bottom row). Each model assumes a constant proportion sterile (12 per cent) and a considerably lower than observed constant proportion not using any method ( 2 per cent). The contraceptive profiles are all intended to be realistic possibilities, although the 50 per cent sterilization rate in Model A may be regarded as unacceptably high in some countries. This first model yields the lowest total unwanted-pregnancy rate of 15.5 per 1000 . In all the models, the pill is used by 20 to 30 per cent, a level that also may be unacceptable given the current medical contra-indications for women at older ages. Perhaps the opti- 
mal realistic scenario is represented by Model $\mathrm{D}$, where pill use is set at 20 per cent (not much higher than the current average of the seven countries), sterilization at 35 per cent (higher than in France and the Scandinavian countries today but lower than in the Netherlands, the U.K. or the U.S.), the IUD and condom together at about their average current use, and where a lower proportion of women is assumed to be using other methods or not using any method. This combination, however, yields an unwanted pregnancy rate of 23.5 , the same as that for the Netherlands.

\section{Abortions averted by contraceptive improvements}

The previous analysis concluded that various improvements in contraceptive practice could result in a 5 to 10 per cent reduction in the annual fertility rate, a small but non-negligible effect on rates that are already very low. We turn our attention now to abortion rather than to fertility and raise the general question of the potential impact on the abortion rate of alternative possible improvements in contraceptive practice.

\section{1. 'Unplanned' pregnancies: definition and method of estimation}

Since abortions are procured by both single and married women of all ages, we enlarge our focus to include all women of reproductive age who are at risk of having an unplanned pregnancy. The term 'unplanned' is used to include mistimed pregnancies (those occurring before they were wanted) as well as unwanted pregnancies (those occurring after the last wanted pregnancy). Many more abortions result from mistimed than from unwanted pregnancies: in the U.S., about 80 per cent of abortions are to unmarried women, and nearly two-thirds are to women under 25 years of age. A woman is defined as being at risk of an unplanned pregnancy if she is using contraception (either to delay or to prevent a pregnancy), or if she is presumably fecund but not using contraception for reasons other than trying to become pregnant. Periods of non-use exposure that consist of waiting time to planned conceptions are excluded, as is gestation time and the premarital period prior to any sexual activity. Non-contraceptive sterility exposure has also been excluded here, because although a few preg- 
Table 7

Estimation of unplanned pregnancies per year per 1000 women aged 20-44: selected countries, circa 1981 .

\begin{tabular}{|c|c|c|c|c|c|c|c|c|c|}
\hline \multirow[t]{3}{*}{$\begin{array}{l}\text { Type of } \\
\text { exposure }\end{array}$} & \multicolumn{4}{|c|}{$\begin{array}{l}\text { Percentage of exposure } \\
(w)\end{array}$} & \multirow{3}{*}{$\begin{array}{l}\text { Unplanned } \\
\text { pregnancy } \\
\text { rate }(p) \\
\text { U.S. } \\
\text { (whites) }\end{array}$} & \multirow{2}{*}{\multicolumn{4}{|c|}{$\begin{array}{l}\text { Unplanned pregnancies } \\
\text { per year } \\
(p) *(w)(1000)\end{array}$}} \\
\hline & \multirow{2}{*}{ Norway } & \multirow{2}{*}{ Sweden } & \multirow{2}{*}{ U.K. } & \multirow{2}{*}{$\begin{array}{l}\text { U.S. } \\
\text { (whites) }\end{array}$} & & & & & \\
\hline & & & & & & Norway & Sweden & U.K. & $\begin{array}{l}\text { U.S. } \\
\text { (whites) }\end{array}$ \\
\hline Pill & 20 & 28 & 32 & 19 & 0.025 & 5.0 & 7.0 & 8.0 & 4.7 \\
\hline Sterilization & 5 & 3 & 28 & 33 & 0.001 & 0.1 & 0.0 & 0.3 & 0.4 \\
\hline IUD & 36 & 24 & 7 & 7 & 0.036 & 13.0 & 8.6 & 2.5 & 2.5 \\
\hline Condom & 23 & 30 & 15 & 10 & 0.023 & 5.3 & 6.9 & 3.4 & 2.3 \\
\hline Other methods & 9 & 8 & 9 & 16 & 0.076 & 6.8 & 6.1 & 6.8 & 12.2 \\
\hline Not using & & & & & & & & & \\
\hline method & 7 & 7 & 9 & 15 & 0.200 & 14.0 & 14.0 & 18.0 & 30.0 \\
\hline Total & 100 & 100 & 100 & 100 & 0.052 & 44.2 & 42.6 & 39.0 & 52.1 \\
\hline
\end{tabular}

Sources: Norway: Noack and Østby (1981); Sweden: Arvidsson et al. (1984); U.K.: Wellings (1986); U.S.: tabulated from the 1982 National Survey of Family Growth data.

nancies will occur to such women, an unknown fraction will be planned. All remaining exposure to risk is included.

As in the preceding analysis, all conceptions that occurred during the recent 12-month period are counted, including current pregnancies, live births, stillbirths, miscarriages and induced abortions. The overall unplanned-pregnancy rate in the U.S. for white women aged 20-44 (teenagers are excluded in order to compare with the European data) is estimated at 0.052 for the year (table 7), which means that one in 20 women at risk will experience an unplanned pregnancy in one year. This rate is reduced by 41 per cent to 0.031 when all foetal mortality (three-quarters of which results from induced abortions) is subtracted. The completeness of reporting of abortions is of obvious importance for our estimates. As noted earlier, the 1982 National Survey of Family Growth estimates of abortion are about 50 per cent below the Centers for Disease Control and the Alan Guttmacher Institute estimates derived from abortion-service providers. In the preceding analysis with white, married, older women, we did not make any adjustment in the number of reported abortions because the available evidence indicates complete reporting for that category. In extending the analysis to the population of white women regardless of marital status, however, we have adjusted the number of reported induced abortions to compensate 
for an estimated 38 per cent under-reporting. Although one can imagine that the propensity to abort might be higher for women using some methods than for those using other methods or for non-users (given the selection of women with certain characteristics into these categories), the empirical results indicate a range of abortion probabilities extending only from a low of 32 per cent of pregnancies aborted for the category 'other methods' to a high of 50 per cent aborted for the pill (based on conceptions in the recent two-year period). The estimated proportion of all unplanned pregnancies (to white women aged 20-44) aborted is 31 per cent. Because the propensity to abort seems relatively unrelated to type of exposure, we have assumed a constant propensity regardless of method. We also assume that the under-reporting of abortions is independent of method.

\subsection{Applications to the United Kingdom, Norway and Sweden}

Given all the assumptions required and also the data available from the European surveys, it seems prudent to restrict the analysis to only a few countries. Because they have more data comparable to those of the U.S., we have selected the United Kingdom, Norway and Sweden. There is the unknown extent of under-reporting of abortion in most surveys; in Norway, the estimate is that abortions were under-reported by 43 per cent, which is quite similar to the estimate for the white population of the United States (38 per cent). In the absence of comparable data on the effectiveness of contraceptive practice in the European countries, we have again used the failure rates for the different methods in the U.S., which in turn are adjusted for the estimated under-reporting of abortions.

The proportion of women in the different countries by type of method currently used and the product of this proportion and the U.S. method-specific pregnancy rates for whites are presented in table 7 , where for purposes of comparison the analysis has been confined to women aged 20-44. Because the proportions of the European women not using contraception are considerably lower than those in the U.S., their cumulative unplanned-pregnancy rates are lower than those in the United States. This is in sharp contrast to the comparisons for unwanted-pregnancy rates (table 5), which are lower in the U.S. because of the higher rates of sterilization among American couples.

The United Kingdom and the two Scandinavian countries have 
similar cumulative unplanned-pregnancy rates that result, however, from quite different contraceptive profiles. In the U.K., the pill and sterilization dominate, while in Norway and Sweden the IUD and the condom are the most popular methods, along with the pill. The contraceptive profile for the U.K. is more like that of the U.S., which because of its higher prevalence of non-use shows the highest unplanned-pregnancy rate.

\subsection{Models of future contraceptive practice}

There is a virtually unlimited number of possible contraceptive scenarios that can be imagined here. We limit ourselves to just four (table 8). Models I and II are designed as possible variants of future contraceptive practice in Scandinavia. They incorporate some increase in pill use and in sterilization, although the latter does not reach the current prevalence in the U.K. or the U.S. IUD use declines but still remains much higher than in the latter two countries. Non-use declines to two per cent in Model I and to zero in Model II. The use of new methods - perhaps some combination of RU-486, implants and injections - is incorporated into Model II. We have assumed an annual failure rate of 0.020 for this category. The reduction in abortions implied by all these changes (assuming no reduction in the methodspecific failure rates) is about one-third in Model I and about 45 per cent in Model II.

Models III and IV are developments that seem more likely for the United Kingdom and the United States. For the U.K., Model III features a moderate increase in sterilization and in condom use and a moderate decrease in the use of the IUD and in non-use, which has the greatest effect. The reduction in the unplanned-pregnancy rate and, by extension, in the abortion rate, would be 46 per cent. For the U.S., Model III would imply a 60 per cent reduction in abortions, almost all of which is the result of a reduction in non-use from 15 per cent to 5 per cent.

Model IV represents the most radical change. The proportion sterilized is projected at 40 per cent, an increase from the 28 per cent current in the U.K. and the 33 per cent in the U.S. New methods are used by 20 per cent, the use of other methods is sharply reduced, and non-use drops to zero. As in Model III, the IUD is down to only two per cent, which is not unlikely in the U.S. because of the financial 
Table 8

Models of improved contraceptive practice for all women aged 20-44 exposed to the risk of unplanned pregnancy, and the implied reduction in abortions.

\begin{tabular}{|c|c|c|c|c|c|c|c|c|}
\hline \multirow{2}{*}{$\begin{array}{l}\text { Type of } \\
\text { exposure }\end{array}$} & \multicolumn{4}{|c|}{ Model } & \multicolumn{4}{|c|}{ Model } \\
\hline & I & II & III & IV & I & II & III & IV \\
\hline & \multicolumn{4}{|c|}{ Percentage using method } & \multicolumn{4}{|c|}{$\begin{array}{l}\text { Number of unplanned pregnancies } \\
\text { per year }(1000)^{\alpha}\end{array}$} \\
\hline Pill & 33 & 30 & 33 & 25 & 8.2 & 7.5 & 8.2 & 6.2 \\
\hline (New methods) & 0 & 20 & 0 & 20 & 0.0 & 4.0 & 0.0 & 4.0 \\
\hline Sterilization & 15 & 15 & 33 & 40 & 0.2 & 0.2 & 0.4 & 0.5 \\
\hline IUD & 25 & 15 & 2 & 2 & 9.0 & 5.4 & 2.5 & 0.7 \\
\hline Condom & 20 & 15 & 20 & 10 & 4.6 & 3.4 & 4.6 & 2.3 \\
\hline Other methods & 5 & 5 & 7 & 3 & 3.8 & 3.8 & 5.3 & 2.3 \\
\hline Not using method & 2 & 0 & 5 & 0 & 4.0 & 0.0 & 10.0 & 0.0 \\
\hline \multirow[t]{2}{*}{ Total } & 100 & 100 & 100 & 100 & 29.8 & 24.3 & 21.0 & 16.0 \\
\hline & \multicolumn{8}{|c|}{ Implied percentage reduction in abortions } \\
\hline Norway & 33 & 45 & 53 & 64 & & & & \\
\hline Sweden & 30 & 43 & 51 & 62 & & & & \\
\hline U.K. & 23 & 38 & 46 & 59 & & & & \\
\hline U.S. (whites) & 22 & 53 & 60 & 69 & & & & \\
\hline
\end{tabular}

${ }^{a}$ Product of method-specific unplanned-pregnancy rate for U.S. whites aged 20-44 and model distributions for percentages using the method.

liability of producers arising out of litigation and the resulting virtual withdrawal of the method from use. Model IV implies a 59 per cent reduction in abortions in the United Kingdom and a 69 per cent reduction in the United States. Again the main reason is the reduction of non-use.

\section{Summary and conclusions}

This analysis has modelled possible improvements in contraceptive practice in order to estimate: (1) their impact on the already low fertility rates in Europe; and (2) their implications for reduction of abortion rates. The first objective involved estimating the unwanted-birth rates to women who want no more births; the second involved estimating the unplanned-pregnancy rates for all women. For reasons of data availability and international comparability, we have relied upon the contraceptive-failure rates calculated for white women in the United 
States and have applied them to the distributions of contraceptive methods estimated in various European fertility surveys.

In connection with the first objective, the conclusion is that the ultimate reduction in general fertility that can be achieved by reduction of contraceptive failure is minimal - certainly under ten per cent. The reductions in unwanted-pregnancy rates can be achieved mainly by substantial increases in the proportion of couples contraceptively sterilized and by a reduction in the non-use of contraception. The main effect of improvements in contraceptive practice will be to reduce the high abortion rates rather than to reduce fertility.

Since most abortions are to women who ultimately want to have (more) children, there is a considerable potential for the reduction of abortions through the improvements of contraceptive practice - the second inquiry in this analysis. Reductions of one-third to one-half of abortions in the countries studied seem within reach, even without any new technology. The main source of such reductions lies in the adoption of any contraceptive method by non-users. For example, if all non-users in the U.K. were to shift merely to the least effective category ('other methods', which includes withdrawal, rhythm and diaphragm) with everything else remaining constant, the implied reduction in abortions would be nearly 30 per cent.

The hypothetical reductions in abortions described here significantly underestimate the true potential impact of improvements in contraceptive practice because they omit consideration of teenage pregnancy. This unfortunate omission is forced on the analysis: in order to achieve comparability across national surveys, the age group forming the highest common denominator - ages $20-44$ - had to be selected. The proportion of abortions that are obtained by teenagers is about one-sixth in Sweden, a quarter in Norway, and over a quarter in the United Kingdom and the United States. Of course, teenagers' contraceptive behaviour may be more difficult to change than that of adults, although one can easily imagine a significant impact of RU-486.

In closing, it seems necessary to reiterate the dependence of this whole analysis on a variety of assumptions that include the use of the U.S. method-specific pregnancy rates for the European estimates and the assumption for all countries that shifts from non-use to use or from one method to another can be effected without influencing the pregnancy rates of both the method discontinued and that adopted (sterilization excepted). Another assumption that is clearly not warranted for 
some contraceptive methods is that failure rates will remain unchanged. With improvements in the pill or in the IUD or even with increases in more effective use, perhaps as a consequence of greater motivation, the method-specific rates may well decline. Some evidence of this has recently been presented for Flanders [Lodewijckx and Impens (1987)]. The objective of this entire exercise has been simply to consider the approximate potential for reductions in fertility and, more significantly, in abortion.

\section{Appendix}

For estimating failure rates, we focus exclusively on conceptions that occurred during the period of interest (defined as the 12-month period between 15 and 3 months prior to the interview), regardless of whether the pregnancy terminated during that period. The following categories of women were imputed as wanting no more births at the beginning of the period:

(1) Respondents who had never been pregnant and whose intention at interview was to have no children.

(2) Respondents whose conceptions occurred only after the start of the period and whose initial pregnancy was unwanted.

(3) Respondents whose pregnancies all terminated prior to the start of the period, if the final pregnancy was unwanted or if this final pregnancy was wanted and the intention at interview was to have no more.

(4) Respondents who had conceptions both before and after the start of the period, if the last pregnancy that ended prior to the start of that period was unwanted; also those respondents whose last pregnancy prior to the start of the period was wanted, who wanted no more at interview, and whose initial pregnancy within the period was unwanted.

\section{References}

Aromaa, K., I. Cantell and R. Jaakkola, 1983, Cohabitation in Finland in the 1970s (Helsinki). Arvidsson, A. et al., 1984, Fertility survey in Sweden, 1981: A summary of findings (World Fertility Survey, London).

Brody, J.E., 1986, Abortion pill expected to be sold in Europe, New York Times, Dec. 18.

Höpflinger, F., 1985, Changing marriage behaviour: Some European comparisons, Genus XLI, $41-64$.

INSEE, 1984, La situation démographique en 1983 - Mouvement de la population (INSEE, Paris).

Koesoebjono, S., 1986, Evolution des ménages aux Pays-Bas, 1960-1981, Population 41, no. 2, 375-378. 
Lodewijckx, E. and I.K. Impens, 1987, The impact of the contraceptive transition on the recent and future development of fertility in Flanders, Paper presented at the European Population Conference in Jyväskylä, Finland.

Noack, T. and L. Østby, 1981, Fertility among Norwegian women: Results from the fertility survey, 1977 (Central Bureau of Statistics, Osio).

Pratt, W. et al., 1984, Understanding U.S. fertility, Population Bulletin (Population Reference Bureau, Washington, DC).

Ryder, N., 1973, Contraceptive failure in the U.S., Family Planning Perspectives 5, no. 3, 133-144.

Sagi, P.C., R.G. Potter, Jr. and C.F. Westoff, 1962, Contraceptive effectiveness as a function of desired family size, Population Studies XV, no 3, 291-296.

Tietze, C. and S. Henshaw, 1986, Abortion: A world review (Alan Guttmacher Institute, New York).

Trussell, T.J. and K. Kost, 1987, Contraceptive failure in the United States: A critical review of the literature, Studies in Family Planning 18, no. 5, forthcoming.

Wellings, K., 1986, Trends in contraceptive method usage since 1970, British Journal of Family Planning, 1986, 15-22.

World Fertility Survey, 1981, Fertility survey in France, 1978: A summary of findings (World Fertility Survey, London). 